HOLMES ROLSTON, III

\title{
THE IRREVERSIBLY COMATOSE: RESPECT FOR THE SUBHUMAN IN HUMAN LIFE
}

\begin{abstract}
In the case of the irreversibly comatose patient, though no personal consciousness remains, some moral duty is owed the remaining biological life. Such an ending to human life, if pathetic, is also both intelligible and meaningful in a biological and evolutionary perspective. By distinguishing between the human subjective life and the spontaneous objective life, we can recognize a naturalistic principle in medical ethics, contrary to a current tendency to defend purely humanistic norms. This principle has applications in clinical care in the definition of death, in the use of life support therapy, in distinguishing ordinary from extraordinary therapy, in evaluating euthanasia, and in the extent of appropriate medical intervention in terminal cases.
\end{abstract}

Attending the irreversibly comatose patient, physicians and family alike often suffer a sense of futility as meaningless days of waiting drag on. The patient is not yet dead, but is dying, perhaps slowly, and the conviction that there is sense in living may collapse before death comes. This conviction, we argue here, will be regained by interpreting this pathetic closing to human life in a larger biological context. Life is present where there are ongoing spontaneous organic functions, even in the absence of mental functions, and such life ought to be given moral respect, although at a level which is reduced from our respect for the full human personality. This level of moral concern, as a matter of fact, is often already operating subconsciously in those who attend the hopeless patient, despite the frequent judgment in recent medical ethics that the spontaneous physiological component to life, by itself alone, is valueless. But rightly understood 'respect for life' includes the vital physical processes which remain after the personality has left. To make this explicit, we first develop a distinction between objective and subjective life, then set

Holmes Rolston, III, Professor of Philosophy, Colorado State University, Fort Collins, Colo, 80523, U.S.A.

The Journal of Medicine and Philosophy 7 (1982), 337-354, 0360-5310/82/0074-0337 \$01.80. Copyright (C) 1982 by D. Reidel Publishing Co., Dordrecht, Holland, and Boston, U.S.A. 
this in an evolutionary context, a distinction and context overlooked in the existing literature. Finally, we contrast a naturalistic principle in medical ethics with the prevailing humanistic one, and develop the practical effect of this principle in clinical care.

\section{OBJECTIVE LIFE AND SUBJECTIVE LIFE}

The most imposing feature of human life is undoubtedly what we variously term self-consciousness, inwardness, deliberating agency, or the experience that there is 'somebody there'. When we respect human dignity we have principal reference to this personal selfhood, which is so much advanced over animal consciousness that we reserve the term "personality" for this level of life alone. Our ethical canons have been finely honed to respect the integrity of such an ego, and both family and physicians will have until recently deeply respected the personality which was constituted in the now wasting body. But all this is gone; the patient's acquired personal and cultural traits have entirely vanished, he or she can defend no values, cannot speak as an 'I,' and has been reduced to a state even below animal consciousness. What we mean by being comatose is that the subjective life once present has lapsed, while objective life remains. This applies even to animal comas, but the high order of human subjectivity, forming a personality, makes its loss especially gripping. After that, what can be said of what remains? Do we respect only the memory of a person who once was there, rather like the way in which his "remains" will be respected after death?

There still continue what we may call the deep structures of life at work in its pursuit. All subjective life is underlain by a physiology typically taken for granted but which now becomes more evident in its survival. The blood and lymph circulate, oxidative phosphorylation and the citric acid cycle continue, proteins are synthesized, ionic levels kept balanced, and bodily defenses conducted, along with hundreds of other biochemical processes. The second most imposing feature of human life is undoubtedly what W. B. Cannon (1932) called "the wisdom of the body," and biochemistry in the half century since he coined that phrase has increasingly been documenting its appropriateness. These structures are not so much the precondition of life as are they the natural, spontaneous face of life, often the only feature present in nonhuman life. Subjective life, where it is present, is inseparably interlocked with objective life.

The time of dying is a time of flashbacks, and the customary 
memories here go with a proper name. But one ought also to recall how much in the lifespan has been physiological. The person who is now dying began as a fertilized egg, underwent prepersonal embryonic development, and even after birth there was for a time no personality formed. The subjective life appeared gradually after objective life was well underway, and no one should be surprised if, towards death, the organic processes, though wearied, can still press on for a time even in the absence of conscious life. All of us once, on the way into the world, crossed the border between the subhuman and the human at a later time than when we crossed the line between life and nonlife. Some of us, on the way out of the world, will again cross these boundaries at separate times. During every second for perhaps two-thirds of a century, these life support capacities have maintained the health of the one now dying. Their astounding reliability has freed the patient to pursue the goals of personal life. This biological vitality may seem now to hurt as a generously endowed body fights on after the conscious mind is enfeebled. But seen in a broad enough perspective, this force that in the last straits stays death is not so much bad as it is ineffective.

Even in the comatose the operation of the body is intelligible. We can almost say that it is intelligent, although in a nondeliberate way. The body typically does things which make sense, given a particular context of stress. There is one kind of logic uppermost in our heads, rational superstructures in the higher brain by which we defend our personal choices. But there are other kinds of logic present unconsciously in our brains and more deeply as the logic in our genes. This other logic wants life and fights effectively for it, even when the conscious mind with its will to life has been lost. Corresponding to those two levels of life, death in humans can be a two-staged process, and when we speak of death with dignity, we may principally refer to a subjective death, but we ought also extend this respect to the dignity of an objective death.

\section{THE PERSON IN EVOLUTIONARY CONTINUITY}

From the organic perspective a continuity across many generations appears. If we ask about the origins of this person, we answer that he or she became self-aware in the cradle, developed that self through childhood on into an adult personality. But now, building on our recognition of the objective life underneath a subjective life, our flashbacks will recall not only an individual organism but ought to 
run further back. This particular individual was only a new beginning carrying on a common life which vastly overleaps any one career. Some of those who attend him may have known the patient's parents, grandparents, and other links in more extended family lines. There are cultural traditions which enter into the formation of the personal, subjective self, but such traits, acquired by education, are no longer evident here. All that continues is the objective biological 'tradition,' and the comatose individual provides occasion for recalling the very ancient succession in which he or she stands.

The self-propagating, spontaneous processes that continue in the comatose were only regenerated in the pregnancy that bore this individual; they were generated across millennia. The struggle for oxygen, for ionic sodium and potassium homeostasis, and for $\mathrm{pH}$ balance first began in Precambrian seas. Here there is coming to finish not merely one personal drama, but there is a local stopping of an almost ageless, global life pulse. Something of that primitive, archetypal drama ought to be recognized as a singular individual comes to death. We need to appreciate the fight deeply carved into us in the evolutionary course. In the short ranges the continuance of these processes can seem senseless, but in the long range this becomes quite intelligible and desirable. Natural selection has worked on all levels of the human organism, not on the conscious level alone, and we are so formed as to maximize the probability of our survival, whether deliberately or nondeliberately. The months or even decades of difficult illness become, under this time span, but a negative instance in a positive vitality which has sustained our humanness for longer than we can recall or remember. If this biological vitality now yields tears in anguish, it has yielded tears in joy a thousand times more often.

Is the patient's mind gone? Unless the case is indeed extreme, the subhuman brain will be partially functional and will leave its traces on the encephalograph. The human brain is composed of phylogenetically older and younger layers, resulting in lower and higher mental levels. Primitive, visceral processes encoded millions of years ago in our mammalian and premammalian ancestors continue when the cognitive processes have lapsed. There still function what MacLean (1970) has called - in phrases from which some shrink the reptilian brain and the older mammalian brain. Nor is human life simply to be equated with neural processes, essential though these are. There are equally vital extraneural physiologies. This organic intelligence remembers what was first learned in experiments 
conducted long before humans arrived, and the continued presence of this 'memory' supports all personal life.

All this is our genealogy, almost literally the logic in our genes, and it continues even when our conscious logic has been defeated. It is the original 'science of life,' which the life sciences have but recently uncovered. Life is a question of an information flow which maintains a cybernetic countercurrent to entropy and decay. In humans, this occurs most dramatically at the subjective level, where it is conscious and deliberate, but it continues from ancient origins at the objective level, somatically and spontaneously. From this perspective, we can now ask: Does it not seem parochial to restrict dignity in life to the personality, finding no respect for this subtending biochemistry still vigilant in the half dead?

\section{THE NATURALISTIC PRINCIPLE IN MEDICAL ETHICS}

A number of ethicists find that with the collapse of the subjective life our duties cease. The permanently insensate patient has no felt interests, none ever again expected, he can take no interest in his welfare, and we can refer to the "interests" of such a patient, claim Joseph and Clorinda Margolis, "only by an extraordinary stretch of the imagination" (1976, p. 17). The right to life, by the restriction of Kurt Baier, refers only to "the quality of experienced life," and so "the right may well end earlier than biological death," since the comatose "human individual may have no qualitative life and so nothing may be a good (or evil) to him" (1979, p. 167f). He is "beyond injury," says Richard Brandt (1975, p. 109). But this is true if interests, goods, and injury attach only to the conscious levels of life where we have ends in view. True, the patient can subjectively take no interest in his welfare, yet the patient objectively takes an interest in his life, as is proved by what the body does in the presence of benefit (nourishment, water) or harm (infection, injury). Physicians still report his condition as being better or worse. Can these no longer be valuational words even in a reduced, naturalistic sense?

Joseph Fletcher depreciates any such suggestion, advocating "the personal versus the physical, or physiological standards of morality." He assigns our subjective humanity to the moral I-Thou realm, with our objective somatic life relegated to the nonmoral It-world. "Physical nature - the body and its members, our organs and their functions - all of these things are part of 'what is over against us'." Physiological nature has "no normative significance," 
but is to be ruled and overruled by personal interests. "To be a person, to have moral being, is to have the capacity for intelligent causal action. It means to be free of physiology!" "The most important insight we gain is that ethical integrity cannot compromise with any naturalistic doctrine." "What is simply given in nature has no moral value." Even when Fletcher briefly moderates this position with a measure of partnership between the person and his body, the most he can suggest is a kind of instrumental respect, Those morally tied to anything further than humanhood cling to an archaic "naive vitalism." They should ask,

Are we not allowing ourselves to be deceived by our self-preservative tendency to rationalize a merely instinctive urge and to attribute spiritual and ethical significance to phenomena appertaining to the realm of crude, biological utility? (1972, p. 194, pp. 211-22).

We wish to argue for valuing what Fletcher and the others so largely cast aside. After the struggle for personal self-possession has been lost, one ought further to respect, albeit in a different ethical relationship, the continuing struggle for biological self-possession. This is not a self-deceived rationalizing about crude vitalistic processes. It is rather the recognition of dignity across the whole of life, an insight into its deep structures, besides which the merely humanistic disdain for the organic sector seems less realistic, less rational, more anthropocentric, not really bio-ethical at all, but an impoverished and shrunken appreciation of the natural element which underlies all life. We hold rather that whatever is biologically vital also carries ethical value.

When the subjective life is gone, the remaining objective life is admittedly incomplete, but does it follow that it is valueless? When the patient was yet self-aware, he counted these biological processes among his goods and interests, roughly summed up as his 'life and health,' for which (if he was religious) he praised God, for which (if he was ethical) he felt entitled by natural right, for which (at a very minimum) he considered himself fortunate. Now exactly the same kind of natural good here continues, diminished in degree in his debilitated condition. Somatically, objectively, he still fights for life and health. From the patient's perspective, if we can still judge such a thing on the basis of his continuing life efforts, the former goodness has not been neutralized by no longer having a subjective owner. So then we who care for him have to ask ourselves what duty is still owed to this objective side of life. 
We need here an ethical naturalism intermediate between the full ethical humanism, which all parties recognize, and the complete collapse of organic interests at death. We term this a naturalistic principle, although there is some sense in which even a personal consciousness is a 'natural' phenomenon, and some features of our humanity - the face, the voice - are nonsubjective. By our contrast here between the naturalistic and humanistic concerns, we mean to distinguish between what is accomplished by deliberate human agency and what is accomplished by the spontaneous natural life as this remains in the comatose patient.

The line where duty ceases as drawn by recent ethicists has tended to be humanistic/naturalistic, with all concern to the left and none to the right. But such a line lately drawn is not the ancient lifeline between the organic/inorganic. They draw too small, too subjective a circle around our personal consciousness, although this is undeniably the differentia which marks off the human species. A broader and more objective principle will respect as sacred not just the personality but the life in us, all of it, including its generic natural quality. Some of the 'quality of life' is protohuman. Much of the wondrous 'essence of life' is still to be found here, even though the still more wondrous essence of personality is missing.

We can expect such a principle to coincide both with deep natural instincts and with primal religious beliefs. So far as natural selection has shaped the sympathies in us for conserving life in ourselves, our kin, and those in our care, these can be expected to operate not only at the conscious personal level but also in the subconscious and at deeper organic levels. These vital processes must have been defended, in every case triumphantly, by all the progenitors of the one now dying, so far as they have thrust life forward to him. That happens amorally in all prehuman ranges of experience, but when life reaches a level of sophistication sufficient to entertain the concept of the 'sacred,' if anything is to be sacred at all, life must first of all be sacred. The very experiencing of this precious elemental vitality, and the urgency of its defense, will produce a conservative belief in its sacredness. There is every biological, evolutionary, and psychological reason to affirm that some duty attaches to life's organic sector.

When ethics arises to evaluate these pro-life tendencies, its primary function will be to warrant life and to discipline the context of its permissible sacrifice, justified as death may be in the service of some larger vision of life. Life must be both asserted and taken, life preys on life, and there is overkill and carelessness. The work of conscience 
is to unify and maximize a concern for the whole phenomenon of life, to defend its rightness at several levels. A cardinal principle in all the ethical systems which have shown any impressive survival capacity (that is, become classical) is that we are to reverence life, where life is something more than humanness. Biology and ethics join in a concern for the life-core, and here the therapist has to notice that there are natural medical powers yet at work in the comatose body, and that to thwart these is to reverse instincts born and beliefs bred into him. Physicians, nurses, and family who abandon the remaining bodily life after the mental life has gone will be cutting against the grain of very primordial levels of experience, against 'gut feelings', and they may find themselves torn between callousness and guilt in doing this.

We thus propose that moral respect be given to the objective component in life, recognizing it for what it is but not for more. This brings ethical concern closer to what we know scientifically, to what we ourselves experience both instinctively and in conscience, it evaluates positively the life that the patient himself is still defending, and it lets us regain a holistic conception of life even when life becomes partial. The argument here is that such a duty is binding, not optional. We must do this; we are not simply permitted to elect such a duty. It is in that sense a hard, not a soft duty. But we also acknowledge that the obligation to protect spontaneous organic processes is weaker than is our stronger duty to protect the personality. This intermediate level of obligation is now being insufficiently recognized.

A moral premise such as this will have use even though it is a somewhat general one. It sets the mood for argument, it provides a reference gestalt against which criticism can work. From the naturalistic principle we cannot derive concrete duties, for it may be variously applied, but still it lays moral constraints on whatever options are available. As one, but only one, of the principles in medical ethics, it is helpful in some of its decisions. It need not give precise absolutes in order to preclude some of the extremes of ethical relativism. We can make this principle operational, as we next do, by attending to the distinction between deliberate and spontaneous actions. What follows is a provisional inquiry into how this principle may be used so as neither to underrespect nor overrespect, but rightly to respect this subhuman quality of life. 


\section{CLINICAL APPLICATION OF THE NATURALISTIC PRINCIPLE}

One ought to protect the comatose dying from two extremes of humanistic zeal: on the one hand from those who care nothing for life at the natural levels, and on the other from those all-concerned to prolong life by every artificial contrivance. The detail of this can only be judged by physicians and others directly involved in particular cases, and any decision requires sensitive attention to many other relevant factors. Still, the naturalistic principle has at least six implications for clinical care.

(1) What death is and when it comes is a question of fact which thinly overlies the moral issue of what our duties are when these cease. A fully physiological understanding of death has long been recognized in the prevailing medical and legal definitions, which include the irreversible cessation of respiration and circulation (Halley and Harvey, 1968). But here we are supplied a criterion upon which to judge the adequacy of various brain death accounts. Such accounts must not be embraced because the higher brain is the seat of our subjective life and personalized individuality (Hamlin, 1964). We will resist proposals that what we have called subjective death and not objective death ought to count in morality (Veatch, 1978). No humanistic redefinition of death can satisfy our biological or ethical concern. On our two staged view, the patient may be dying, but he is not yet dead when he loses his humanness.

The recent proposal for defining death made by the President's Commission for the Study of Ethical Problems in Medicine and Biomedical and Behavioral Research, on the other hand, adequately protects the naturalistic level of life which we value (1981). This was likewise intended by the earlier, but more confused, report of the Ad Hoc Committee of the Harvard Medical School (1968). The President's Commission recommends:

An individual who has sustained either (1) irreversible cessation of circulatory and respiratory functions, or (2) irreversible cessation of all functions of the entire brain, including the brain stem, is dead (p. 2).

The two disjunctive clauses are really windows into the same event, the loss of systemic, integrated organisrnic functioning. Respiration is under the control of the brainstem, and the two typically fail together.

It seems that only very rarely in medically contrived extremes 
(involving hypothermia or certain drugs) does the case arise where there is no brain functioning detectable on an EEC and yet spontaneous cardiorespiratory activity (Brierley et al., 1971). While there is a certain biological correctness to the judgment, arising from the experience of breath and pulse, that spontaneous cardiorespiratory activity is a more elemental, more ancient form of vitality than is nervous activity, the two are really inseparable in human life. The few counterexamples are likely to be too artificial to trouble our basic principle about protecting natural life.

We do need in brain death accounts to draw the lines in the right places. We ought not to be drawn to brain death accounts because the higher brain is the sponsor of cognitive functions. But, since the lower brain is the regulator of respiratory functions, brain-based definitions can detect the same loss of spontaneous life as can heart-lung criteria. It is not the death of the mind, but the death of the entire brain which counts.

(2) What we here protect is spontaneous physiological functioning, and we need to distinguish this from artificial cases. At this point the definition of the President's Commission is not explicit enough about the element of spontaneity, although this is adequately discussed in their accompanying explanation. Respirators and heart stimulators are warranted where, hoping yet to save the personality in life, one intervenes to prolong a failing physiology. It is the chief business of medicine to be in this humanistic sense self-assertive, and this is consistent with the larger cultural process, of which medicine is a part, where the mind works to assure its own upkeep and that of other minds.

But here we are reduced to a lesser case. One wonders whether, after the mind has perished, the medical genius should by artifice assert a failing neural, cardiovascular, or respiratory physiology. The naturalistic standard means that, where the personal life cannot be regained by any deliberate manipulation, the ensuing life process needs to be sustained only insofar as this can be construed as naturally ongoing and not artificially inserted, terms which at this point are approximate equivalents of ordinary rather than extraordinary therapy.

The hospital is one of the most artificial or deliberately built environments conceivable, and there we too often forget how the basic life process is still quite fundamentally spontaneous. This deliberate and careful control is fitting for our strong duty to protect persons, in whom life is also carried on deliberately. But here our 
duty reverts to a binding but weaker one to protect a remaining biological vitality where life takes place only spontaneously. We morally ought, as it were, to permit life spontaneously to occur, but we are not bound to guarantee it. We supply ordinary necessities, including the usual environmental supports: foods, fluids, air, warmth. But support becomes extraordinary where the heart will not beat nor the lungs function without stimulation. In a biological perspective, the spontaneous life processes have naturally disappeared and are only contrived and put there.

The difficult cases are the intermediate ones, owing to the partial nature of much supportive therapy, and we recognize that clinical treatment often tends to obscure issues that logically and ethically we need to keep separate. Intravenous nutrition and an oxygenenriched atmosphere, though artificially administered, can still be construed as ecological support. In general, what one wants to supply are the materials of life, but not life itself. An artificial respirator in some sense supplies both, additional oxygen as a life material, but ventilation as a life process. What we need to determine, if we can, is whether the patient's control centers which govern respiration have failed so that the oxygen alone would be insufficient, and here the EEG will provide usually reliable data.

In the presence of the now rather frequent anomaly of a patient with no brain functioning at all, whose cardiorespiratory processes continue not because he initiates them but because we (via machines) instigate them, we can say that such a patient is beyond coma, he is dead, and cease treatment. The spontaneity we wish to protect is not mere cellular activity or reflexive activity, but is rather the systemic, informational, organismic integrity of a self-directed physiological life.

Clinical care is morally bound to help at boundaries of life where environmental exchange takes place, in input and output, so to speak; but at this level of moral binding we are not required to move into the control centers of the body, whether neural or genetic, to institute metabolism, to command cardiorespiratory activity previously controlled by brain and spinal column, or to synthesize enzymes and sustain biochemistries previously keyed by information in the genes. We keep the patient hydrated and nourished, protected from injury and infection. The normal elimination of wastes will probably be artificially furthered, as will certain sanitary measures. But the use of medications, blood transfusions, hemodialysis, tracheostomy, and the oxygenator will seem progressively less justified, as 
they more and more substitute a synthetic mimicking of the natural physiology. Still, one does not cross a sharp line but a twilight zone. Perhaps within the naturalistic concern here required, there is place for some further calculus of therapy, more or less ordinary, proportionate to the vigor of the remaining life.

Judgment is further complicated when these procedures are instituted while the recovery of the person is still hoped for, as they should be, but afterwards one has to ask whether to continue what, on the basis of the naturalistic principle, he would not now start. If we can recognize the shifting basis of our duties, we may want to reduce the level of clinical care. In the hospital these very old, natural life processes are put in a very recent and artificial context, and the medical craft can produce anomalies before which we are morally puzzled. This will result in some questions which we cannot unambiguously answer. But eventually at least, one comes to the judgment that not only is all human life gone, but that there is not any subhuman life left either, nothing really of the spontaneous organismic wholeness, since the latter self-directing too is gone at its cores and would not continue without this exotic human contrivance. This is what is extraordinary about respirators, heart stimulators, and brain electrodes, rather than the mere fact that they are relatively novel and unconventional. We 'pull the strings' and make of the organism a 'puppet.' That is permissible if we are protecting or hope to regain a person; but it is not required by any respect for organic integrity, indeed it rather violates it. Such intervention is morally desirable when we step in at the personalistic level, but is not appropriate when we step back to the naturalistic level.

(3) Euthanasia is commonly divided in to active and passive forms, and the naturalistic norm enables us to judge the difference, as it applies to the comatose. ${ }^{1}$ In active euthanasia a human agent deliberately executes still viable natural life, and this may be advocated by those who find the comatose life pointless, without interests or rights. But any who respect the continuing objective life will oppose such killing, if its principal rationale is merely of this kind. Some stronger conditions will be required to justify it, as might be the case if continuing this comatose life were to impose unbearable emotional or financial burdens, a greatly reduced quality of personal life on the part of those who care for him. This harm can in some cases be more negative than any positive result from showing respect for the naturally remaining comatose life. But this needs to be argued in the light of some duty also to the biological processes. 
Passive euthanasia is noninterference in the collapse of life, permitting natural death to occur unopposed. Only the studied restraint of human agency is required. There are contexts of personal life where withholding a lifesaving drug or administering a poison have about the same moral effect, malicious or benevolent, thus eroding the value of the distinction between active and passive euthanasia. But at the level we are now considering, these terms correspond to an artificial and a natural death in a morally relevant way. An administered poison blocks the ongoing vital processes, while, after assuming the ecological support already described, the withholding of a metabolically active drug results in the natural failure of somatic processes which, at this intermediate level, we are no longer obligated to support.

We have a moral duty deliberately, actively, even extraordinarily to protect (or at least to offer protection until refused) the subjective personal life, using feasible and practical medical manipulation, for here one person is caring for another person. Beyond this, we have a moral duty nonoptionally but only passively and ordinarily to protect the objective, automatic life, so far as it is naturally viable. We are not bound to use our minds mindlessly to contrive the repair of physiology that of itself would cease. There is even a point past which we logically cannot preserve objective natural life, for to do this we must convert it to an unnatural life. Any manipulative intervention at the life-core destroys its natural spontaneity. If we mark out two cybernetic levels involved in the governing of human life, the genetic-physiological and the intellectual-cultural, we are not obliged by interference to prolong a natural cybernetic system which has collapsed below the point of supporting any personal life. That system is yet to be respected, even in this incompleteness, for it is still life, but we drop back to a different operational principle biologically, and a different operational principle is ethically appropriate.

In one of the more sensitive justifications of active euthanasia, Ellen Kappy Suckiel defends the fact that the permanently unconscious patient can still have interests and rights, but nevertheless she maintains that under certain circumstances the patient's death, deliberately executed by physicians and family, may be a positive benefit to the patient himself, apart from whether it benefits others. "Dying is not always bad: it is sometimes better for a person to die than to continue to live." "If dying is not always bad, then killing may not always be wrong." "Human choice and human activity may 
function to palliate what might metaphorically be called the injustices or cruelty of nature. It is difficult to see what is wrong about this" (1978, pp. 47-48).

Our naturalistic principle questions whether "the injustices and cruelty of nature" is the right metaphorical gestalt in which to see these spontaneous medical powers still at work. We have difficulty seeing what is unjust about them. To the contrary, they continue, as it were, to justify life; and in the insensate, nonsuffering patient it is difficult to see what is cruel about them. Operating as we now are at the level of objective life, with all experienced life gone, benefits and harms to the patient have to be biologically defined. If we attempt to kill him he will, of course, somatically defend himself. Resisting death is what he is principally and unambiguously doing. The patient can voice no subjective will, but he yet has "an objective will" evidenced in his fight for life, a will which is only semi-metaphorical. Objectively, he has a poor or low quality of life, but his death cannot be in his interest and benefit, for when death comes even that quality expires.

There are evils worse than death, and there are values for which we will sacrifice life. But have we such an evil or such a value here? The only such evil to be experienced by the patient might be suffering, which, subject to our discussion to follow, is not possible for the comatose. His remaining value just is his life. We might suppose what he would elect to do, were he yet capable of decision. If his living on is especially costly to others, we might decide for him on deliberate death, but this cannot be conceived on the model of a benefit to him. It is a sacrifice of his remaining biological life for the benefit of others. If we consult his remaining objective life alone, we will not actively override it. This natural component of life is very old, fundamental, mysterious, precious, still incompletely understood, and we show more moral respect to let the organism in its spontaneous centers of control judge for itself when life is over.

(4) The naturalistic standard may come into conflict with our kind impulse to eliminate suffering. Here again a question of fact is intertwined with a question of duty. Pain is experiential, and it is difficult to say empirically whether and how much the comatose do suffer, since they are not conscious and their sensitivities marginal or unknown, even though the bodily organism is in distress. Though it has a physical origin, pain belongs to the subjective life, and most medical decisions about its relief are at the level of compromising by sedation a personal life which has become anguished. In such 
contexts an already debilitated personal life is suppressed in order to reduce suffering. But this humane level is not under consideration here, where the subjective life has already collapsed. How much of pain remains in the objective natural life? Subhuman life can still suffer; pain is possible through a range of animal consciousness, but in a deep coma all of that level of sentience, which in humans is allied with the personal consciousness, will have lapsed.

Palliative therapy that removes the appearance of pain is in order, and those who attend the comatose will find some comfort in this objective relief, even though denied access to how far pain is experienced. The decision becomes difficult when such direct pain killing therapy is also indirectly life killing, as when narcotics depress respiration. Here some will prefer the relief of pain, if there can be such relief in the comatose, even if it shortens objective natural life. At this point the naturalistic principle must collide with what we interestingly call a humane principle, and the results will often be a compromise.

In the comatose dying we cannot heal, and we may at least reduce any hurt. But this humane principle is not the sole ethical factor operating here; it can be checked by our respect for the subhuman vitality. Where we cannot have a comfortable life, the naturalistic principle asks us, in measure at least, to prefer life in distress, possibly in some pain, over the termination of life merely to escape an ordeal. This is consistent with the evolutionary struggle and with the will to live still somatically evident in the organism, which does not wish "a gentle and easy death" (euthanasia). It is consistent with classical medical ethics and with a respect for the whole of life. We are morally required to respect life even as it endures stress. There is always dignity in the fight for self-preservation, and very much of that fight remains in the comatose struggle. Here pain and ease are not coextensive with good and evil.

(5) In any donated organs, these biological processes will be continued precisely because of transplanting. In the recipient, a personal life is saved by this, and that is morally commendable. It is better to transplant than to bury a viable organ; it also, if incidentally, respects the continuing physiological life in the organ. In some cases, our strong duty to protect a person (in the recipient) will override our weaker duty to protect organic life (in the comatose). What checks this is that to transplant from the living we have to sacrifice one functioning organic life (the comatose) in behalf of another which has organically failed (the organ-needing recipient). 
Our present principle and practice, except for extraordinary cause, is not to violate the organic integrity of a still functioning, though irreversibly comatose body, vivisecting to gain an organ. Death ought first to be pronounced by fully naturalistic criteria, without regard to whether organs are sought. We cannot further argue this here; for some implications, see Jonas (1974). What we can say on the basis of our analysis is that we ought not to hedge the definition of death, pretending that the comatose is already dead, having lost his humanhood. We must rather include in the calculus the remaining life-value of the moribund donor, our intermediate level of duty here, and stay alert to what sacrifices are being made.

In current practice, the distinction here is masked by the use of respirators, turned on to support a whole life, but left on to support an organ, continued not retrospectively for the patient lately deceased but prospectively for the living recipient. In the emotional context in which this occurs, there is all the more call for rigorous insight into what is going on beneath the surface, both from biological and from ethical perspectives. Apart from such transplanting (and possibly some medical research), it should also be clear that, from the perspective of the naturalistic principle, it is both pointless and self-defeating to contrive the continuance of vital organs, as this very contrivance destroys the spontaneous life which the principle bids us to respect.

(6) When only the subtending mammalian processes remain, and moral concern reverts from a humanistic to a naturalistic mode, one can ask whether the treatment of the comatose dying differs from that given to dying animals for which we elect to care. It seems best to acknowledge this problem and pass over it, since the issue of animal rights is complex and currently in much flux. A healthy animal has a completeness to its life, more life than does the comatose human. If both are comatose, the surviving mammalian processes are very much the same. But it does not follow that we ought to be indifferent to whether what is dying is man or beast, and clearly the physician and the veterinarian do differ in the therapy provided to insensate patients.

The depressed organic body is still human anatomically, and we have but to recall the somatic dimensions of personality, as expressed for instance in face and hands, to see that the vehicle of its expression may continue to be the object of our special concern, even when only animal physiology remains, as this may not be the case for pets in their last distress. The physical body has been the entire means of 
mediating the personality, to which we have no other access, and this morphology is yet present in a waning vitality. In this sense more than animality remains, the objective features of personality are partially here, and this will heighten the level of our care. This is in some degree an argument from sentiment, since the personality in this human body is gone, but sentiment is one component of moral concern. It may be that the extra care here exercised is to be justified more on this basis than on the basis of the naturalistic principle alone.

A human life is a personal history, significantly exceeding spontaneous biology, and medicine ought to protect persons. But where this humanistic struggle has been lost, life returns to the plane of natural history, with its peculiar dimensions of moral respect. The hospital is such a humane place, and medicine spends so much energy interrupting nature, that it is difficult for us to think of clinical care as an arena of natural history. But we can and ought to do this especially at life's boundaries, at birth and death. Death is the last great struggle which must come by the inexorable ordination of nature. Here part of the dignity of a living being is revealed in its sustained resistance to death. The organism ought to live on while it has spontaneous defenses as these come down from the evolutionary, biological lineage. But with the person gone, this latter dignity is not enhanced by artificial contrivance. Ethical respect here means a resigning of the medical brilliance so impressively employed in other contexts to defend the person. Towards the end, we are morally satisfied when, in a manner often difficult to discern, we let life take its natural course.

\section{NOTE}

1 We are not here entering a related, but different question whether the patient who is yet self-aware, and who has a right to live, has also a duty to live such that he cannot voluntarily (through a physician's mediacy) elect to terminate his life, that is, exercise a right to die, declining his right to live. Such a decision would, of course, override the objective, somatic ongoing of his body, about which we are here concerned, but he might have reasons sufficient for this. Any justifiable sacrifice of life endorses such overriding. In cases of prerequested active euthanasia the physician and family will have to inquire whether the comatose patient's earlier request rightfully can override that respect which they now have for his remaining life. 


\section{REFERENCES}

Ad Hoc Committee of the Harvard Medical School to Examine the Definition of Brain Death: 1968, 'A definition of irreversible coma', Journal of the American Medical Association 205,337-340.

Baier, K.: 1979, 'Technology and the sanctity of life', in K. E. Goodpaster and K. M. Sayre (eds.), Ethics and Problems of the 21st Century, University of Notre Dame, Notre Dame, Ind., pp. 160-174.

Brandt, R.: 1975, 'A moral principle about killing', in M. Kohl (ed.), Beneficent Euthanasia, Prometheus Books, Buffalo, N.Y., pp. 106-114.

Brierley, J. B., Graham, D. L, Adams, J. H., and Simpsom, J. A.: 1971, 'Neocortical death after cardiac arrest',. The Lancet 2, 560-565.

Cannon, W. B.: 1932, 1963, The Wisdom of the Body, W. W. Norton, New York. Fletcher, J.: 1972, Morals and Medicine, Beacon Press, Boston.

Halley, M. M. and Harvey, W. F.: 1968, *Medical vs legal definitions of death', Journal of the American Medical Association 204,423-425.

Hamlin, H.: 1964, 'Life or death by EEG', Journal of the American Medical Association 190,112-114.

Jonas, H.: 1974, 'Against the stream: Comments on the definition and redefinition of death', in Philosophical Essays: From Ancient Creed to Technological Man, Prentice-Hall, Englewood Cliffs, N J., pp. 132-140.

MacLean, P. D.: 1970, 'The triune brain, emotion, and scientific bias', in F. O. Schmitt (ed,), The Neurosciences Second Study Program, Rockefeller University Press, New York, pp. 336-349.

Margolis, J. and Margolis, C.: 1976, 'On being allowed to die', Humanist 36, January/February, 17-19.

President's Commission for the Study of Ethical Problems in Medicine and Biomedical and Behavioral Research: 1981, Defining Death, U.S. Government Printing Office, Washington.

Suckiel, E, K.: 1978, 'Death and benefit in the permanently unconscious patient: A justification of euthanasia', Journal of Medicine and Philosophy 3, 38-52.

Veatch, R. M.: 1975, 'The whole-brain-oriented concept of death: An outmoded philosophical formulation', Journal of Thanatology 3,13-30. 